\title{
Uptake and Distribution of Boron in Coconut and Paurotis Palms
}

\author{
Timothy K. Broschat ${ }^{1}$ \\ University of Florida, Fort Lauderdale Research and Education Center, \\ 3205 College Avenue, Davie, FL 33314
}

Additional index words. fertilization, leaf nutrient analysis, sodium borate, boron deficiency, Acoelorrhaphe wrightii, Cocos nucifera

\begin{abstract}
Natural distribution patterns of boron (B) among leaves within a canopy, among leaflets within a leaf, and within single leaflets were determined for coconut palm (Cocos nucifera L.) and within leaves for paurotis palm [Acoelorrhaphe wrightii (Griseb.\& H. Wendl.) Becc.]. Leaf B concentrations did not vary significantly among leaves within the canopy or among leaflets within a single leaf for coconut palm, but basal leaflets of paurotis palm had higher $B$ concentrations than central leaflets. Boron concentrations were significantly higher toward the tips of individual leaflets in both species. Application of Solubor to the soil significantly increased leaf $B$ concentrations in all leaves of coconut palm after 2 months as well as in new leaves produced up to 6 months later. Application of Solubor as a leaf axil drench was much less effective in increasing foliar $B$ concentrations than soil treatment.
\end{abstract}

Boron deficiency is a common and widespread disorder of palms throughout the world (Broschat, 2007a; Corrado et al., 1992; Elliott et al., 2004; Kamalakshiamma and Shanavas, 2002). Boron deficiency can be extremely transient, affecting developing leaves for as little as a day or 2 before normal growth resumes (Broschat, 2007a). Under these conditions, the effects of a temporary deficiency only become visible when the affected developing leaf emerges 4 or more months after the deficiency occurred. Palms may experience multiple alternating periods of B sufficiency and deficiency during the time that it takes for the first affected leaf to emerge. Thus, visual deficiency symptoms are an indication that a temporary $\mathrm{B}$ deficiency has occurred before leaf emergence but provide no clues as to the current B status of the palm (Rajaratnam, 1973). Similarly, leaf analysis for $\mathrm{B}$ content may not always be a good indicator of current B status (Oertli, 1994).

Boron deficiency can also be chronic, affecting a series of successive leaves as they develop. As an immobile element, B deficiency causes leaflet fusion and malformation, truncation, and reduction in the size of newly emerging leaves (Broschat, 2007a; Corrado et al., 1992; Kamalakshiamma and Shanavas, 2002). These symptoms could be confused with deficiencies of other micronutrients such as manganese, zinc, or copper, herbicide toxicities, or even bud rot diseases (Broschat, 2007b; Elliott et al., 2004). Where

Received for publication 12 Aug. 2011. Accepted for publication 10 Oct. 2011.

This research was supported by the Florida Agricultural Experiment Station.

I thank Anita Durden, Susan Thor, and William Latham for their assistance in the project.

${ }^{1}$ To whom reprint requests should be addressed; e-mail tkbr@ufl.edu. visual deficiency symptoms are insufficient to diagnose chronic B deficiency, leaf nutrient analysis can be useful (Mills and Jones, 1996). An understanding of natural B distribution patterns within palm canopies and leaves is necessary to determine which leaves should be sampled for analysis (Rajaratnam, 1973). Such studies have been done for other nutrient elements in coconut palm (Amalu et al., 1988; Broschat, 1997), Canary Island date palm (Phoenix canariensis Chabaud) (Broschat, 1997), and edible date palm ( $P$. dactylifera L.) (Reuther, 1948), but B distribution has only been examined in African oil palm (Elaeis guineensis Jacq.) (Rajaratnam, 1972a). Because Broschat (1997) found that some elements may be mobile in one palm species, but immobile in another, the results obtained for African oil palm may not apply to coconut palm. Furthermore, these four species are pinnate-leaved palms. There is no published information on $\mathrm{B}$ distribution within the leaves of any palmate-leaved palm species, which may differ substantially from pinnate-leaved species.

There is very little published research on the treatment for B-deficient palms. Soil applications of 40-700 g of borax $\left(\mathrm{Na}_{2} \mathrm{~B}_{4} \mathrm{O}_{7}\right.$. $10 \mathrm{H}_{2} \mathrm{O}$ ) per palm per year have been suggested by Dickey (1977), Kamalakshiamma and Shanavas (2002), and von Uexkull and Fairhurst (1991). Some of these authors also suggest applying borates in the leaf axils, but they provide no data on the relative effectiveness of these two methods. Rajaratnam (1972b) studied the uptake of B applied to the soil and leaf axils in African oil palm, but equivalent studies have not been published for coconut palm. The objectives of this study were 1) to document the natural B distribution patterns in leaves of coconut palm, a pinnate-leaved species and paurotis palm, a palmate-leaved species; and 2) to determine the effects of soil and leaf axil-applied B on the B content of coconut palm leaves of various ages over time.

\section{Materials and Methods}

A block of 'Fiji Dwarf' coconut palms $\approx 15$ years old and $3-6 \mathrm{~m}$ in overall height was used for these experiments. The palms were spaced $6 \mathrm{~m}$ apart and were growing in a Margate fine sand soil (siliceous, hyperthermic, Mollic Psammaquent) with a $\mathrm{pH}$ of 6.1 and cation exchange capacity of $3.1 \mathrm{mEq} /$ $100 \mathrm{~g}$ in Davie, FL (lat. 26 4' $56^{\prime \prime} \mathrm{N}$, long. $\left.80^{\circ} 1423^{\prime \prime} \mathrm{W}\right)$. The paurotis palms were growing the same location and were $\approx 26$ years old with an overall height of $\approx 6 \mathrm{~m}$. They received no supplemental irrigation nor had any fertilizer been applied during the previous 2 years. None of the palms in these experiments exhibited any symptoms of $B$ deficiency at the time of the experiments.

On 14 Apr. 2005, the two central leaflets from each leaf in the canopy of 12 replicate coconut palms were collected for B analysis to determine the natural distribution of $\mathrm{B}$ among leaves within a palm canopy. Leaves were numbered with a permanent marker on the petioles, assigning leaf0 to the unopened spear leaf, leafl to the next youngest leaf, and so on to the bottom of the canopy. This numbering system was used in all experiments and as successive new leaves emerged, they were assigned numbers of leaf-1, leaf-2, etc., in the order in which they emerged.

From these same 12 coconut palms, a pair of leaflets from the base, center, and tip of the youngest, fully expanded leaf (usually leaf2) was harvested to determine the distribution of B among leaflets within a single leaf. To determine how $\mathrm{B}$ was distributed among leaflets of a palmate-leaved palm, the youngest, fully expanded leaves from six replicate paurotis palms were also sampled. In these palms, a pair of leaflets was sampled from the base and from the central portion of each leaf blade. In addition, the central leaflets from the youngest fully expanded leaves of the coconut and paurotis palms were further divided into thirds with the leaflet bases, center sections, and tips analyzed separately to determine the distribution of $\mathrm{B}$ within individual leaflets in pinnate and palmateleaved palms.

After obtaining the initial leaf samples, the coconut palms were treated either with a soil drench or a leaf axil drench of B. Six palms were treated by drenching the root zone under each canopy with $20 \mathrm{~L}$ of a solution containing $35 \mathrm{~g}$ of $\mathrm{B}$ from Solubor $\left(\mathrm{Na}_{2} \mathrm{~B}_{8} \mathrm{O}_{13} \cdot 4 \mathrm{H}_{2} \mathrm{O}\right)$ (US Borax, Valencia, CA) on 14 Apr. 2005. An additional six palms were not treated with $B$ and served as control plants. Another six palms were treated by pouring $2 \mathrm{~L}$ of a solution containing $225 \mathrm{mg}$ B from Solubor into the axils of the upper leaves on 27 Apr. 2005. The treatments used in this experiment were based on the recommendations in Dickey (1977) for coconut palms in Florida. The experimental design was split plot resulting from the potential overlap in the root systems of individual palms. Treated and 
untreated blocks of palms in these experiments were located greater than $20 \mathrm{~m}$ apart.

At 1 and 2 months after B application, the central leaflets from each leaf within the canopy of treated and control palms were harvested for B analysis to determine the rate of uptake and distribution within the canopy from soil application. For each palm, central leaflets from the youngest fully expanded leaf (leaf2 at the time of $\mathrm{B}$ application) were harvested for B analysis at 1, 2, 3, 4, 5, and 6 months after treatment. The movement of B into leaves that emerged after treatment was also determined by sampling newly emerging leaves at 1, 2, 3, 4, 5, and 6 months after treatment. The change in B concentrations at Months 1 and 2 for each leaf was calculated as the $\mathrm{B}$ concentration at 1 month minus the $\mathrm{B}$ concentration at 0 months and $\mathrm{B}$ concentration at 2 months minus the $\mathrm{B}$ concentration at 0 months, respectively. Similar sampling was done for coconut palms treated with $\mathrm{B}$ in the leaf axils starting 6 weeks after application and ending after 5 months.

For leaf $\mathrm{B}$ analysis, the unwashed leaves were dried at $60{ }^{\circ} \mathrm{C}$, ground, and digested using a nitric acid--hydrogen peroxide method (Huang et al., 2004). Boron determination was performed by inductively coupled plasma emission spectroscopy (Keren, 1996). Analysis of variance with mean separation using the Waller-Duncan k-ratio method or regression analysis was performed on the leaf B data using SAS Version 9.2 Proc GLM (SAS Inst., Cary, NC).

\section{Results and Discussion}

Boron is considered immobile in most plant species and thus would be predicted to accumulate to a greater extent in older leaves than younger ones (Brown and Shelp, 1997). Such an increase in B concentration with leaf age was found to occur in African oil palm (Rajaratnam, 1972a). In this study, leaf B concentrations in unfertilized coconut palms were statistically similar among all leaves from position 1 (youngest leaf) to 21, the oldest leaf (data not shown). Thus, when sampling for $\mathrm{B}$ analysis in this species, leaf position may be less important than it is for other elements (Broschat, 1997). Still, the youngest fully expanded leaf should be a better indicator of current B status than older leaves as a result of its more recent development.

When leaflets from the basal, central, and terminal regions of coconut palm leaf 2 were compared, there were no significant differences in foliar B concentrations (Fig. 1A). A similar non-significant pattern was observed among leaflets of another pinnate-leaved species, the African oil palm (Rajaratnam, 1972a). However, when similar comparisons were made among leaflets at the leaf base or leaf center of paurotis palm, a palmate-leaved species, basal leaflets were found to contain significantly more B than leaflets sampled from the center of the leaf blade (Fig. 1B). The reason for the difference between basal and central leaflet $\mathrm{B}$ concentrations in this species is not clear because all leaflets in a
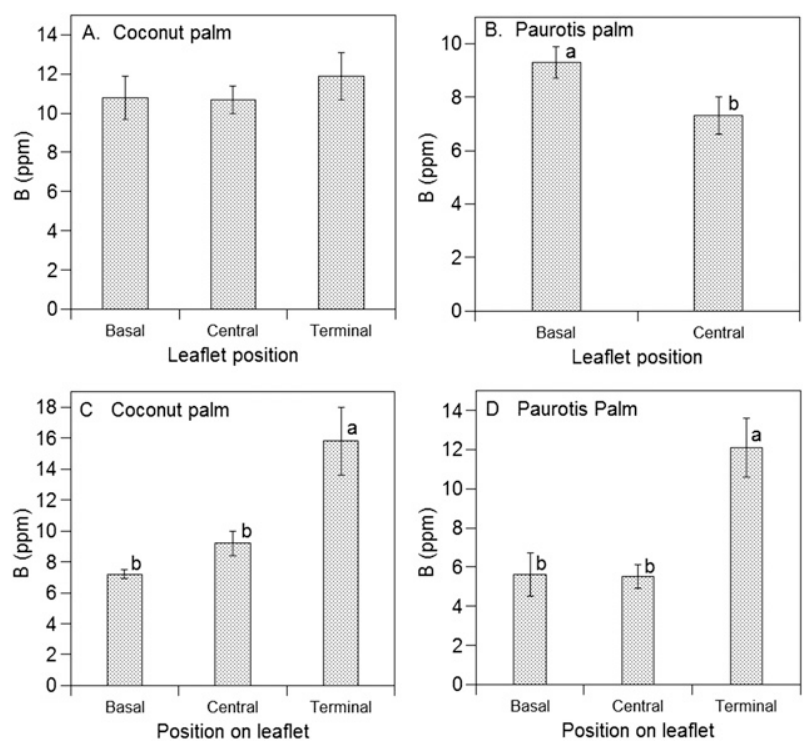

Fig. 1. Effects of leaflet position within a leaf of coconut palm (A) and paurotis palm (B) and sampling position within the central leaflets of the youngest fully expanded leaf of coconut palm $(\mathbf{C})$ and paurotis palm (D) on foliar boron concentrations. Different letters above bars indicate statistical differences between means at $P<0.05$ level using analysis of variance and the Waller-Duncan k-ratio method. Vertical lines represent SES. $\mathrm{n}=12$ (coconut) or 6 (paurotis).

palmate-leaved palm are of equal length and radiate from a single anatomical structure, the hastula (Tomlinson, 1990). Basal leaflets may have greater transpiration rates than central leaflets as a result of their location at the leaf margin. This could enhance B accumulation in these marginal leaflets.

In contrast to the lack of differences in $\mathrm{B}$ concentrations among leaflets along the rachis of a coconut palm, B concentrations within a leaflet increased significantly toward the tips of coconut and paurotis palm leaflets on leaf2 (Fig. 1C-D). In African oil palm, Rajaratnam (1972a) showed steep increases in foliar B concentrations from leaflet bases to tips. Because B is believed to be carried primarily within the transpiration stream of plants, it would be expected to accumulate in leaflet tips where water loss from transpiration is greatest (Kohl and Oertli, 1961; Oertli, 1994; Rajaratnam, 1973). Thus, when selecting palm leaflets for B analysis, consistency in sample selection is important. Reference values for $\mathrm{B}$ concentrations in palms are typically based on entire middle leaflets of the youngest fully expanded leaf (Mills and Jones, 1996).

When Solubor was experimentally applied to the soil surrounding coconut palms, there were no changes in $\mathrm{B}$ concentrations in leaf2 until 2 months after application (Fig. 2A). However, 1 month after application, leaf0, which was the unopened spear leaf at the time of application, contained significantly more B than similar-aged leaves of control palms (Fig. 2B). Two months after application, leaf-1 (the youngest expanded leaf at that time) B concentrations were much greater than similar-aged leaves from control palms. The trend in leaf B concentrations was similar for the youngest leaf on each palm (Fig. 2B) to that of leaf2 (Fig. 2A). Thus, B taken up from the soil moves into leaves produced even 6 months after application, although the concentration of B in the youngest leaves decreased between 2 and 5 months after application $\left(r^{2}=0.17, P<0.0001\right)$ (Fig. 2B).

For older leaves, soil-applied $B$ generally did not significantly increase leaf B concentrations during the first month after application (Fig. 3A). However, 2 months after application, soil-applied B increased leaf B in all leaves (Fig. 3B). The magnitude of the increase in leaf $\mathrm{B}$ concentrations decreased significantly with leaf age $\left(r^{2}=0.20\right.$, $P<0.0001$ ), however, for treated palms (Fig. 3B).

Although the soil was not analyzed for B content, it is likely that this prolonged movement of B into newly developing leaves is a result of residual $B$ in the soil after treatment. Because B is considered immobile in most plants, any re-translocation of B from older to younger leaves would have resulted in a gradient of decreasing leaf B with increasing leaf age, a pattern not observed in this study (Broschat, 1997; Brown and Shelp, 1997). Rajaratnam (1972b) demonstrated limited movement of B within leaves and leaflets, but only acropetally within these tissues or in the direction of the transpirational stream in African oil palm.

Although B sufficiency levels have not been published for coconut palm, the normal range of B concentrations in African oil palm and other palm species is generally between 10 and $50 \mathrm{ppm}$ (Mills and Jones, 1996; Reuter and Robinson, 1986). If these values are applicable to coconut palms, then the control palms in this experiment were only marginally sufficient in B, whereas soil-treated palms achieved B concentrations above the normal range for other palm species without any evidence of toxicity symptoms. 

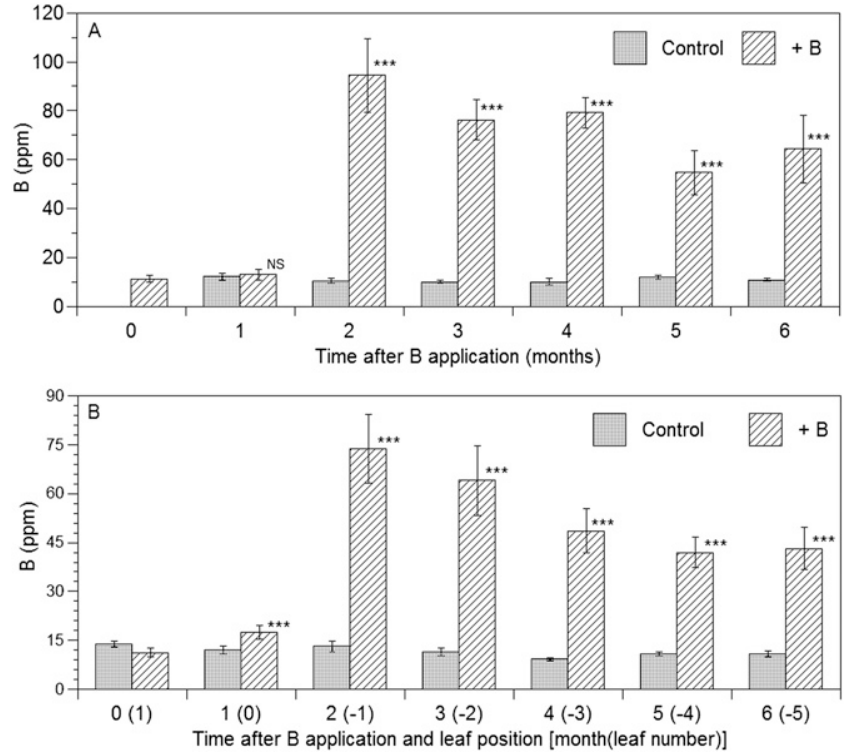

Fig. 2. Effects of soil-applied boron (B) on coconut palm B concentrations in leaf2, the youngest fully expanded leaf at the time of application (A) and the youngest fully expanded leaf at the time of sampling (B). Boron was applied at 0 months with control plants receiving no B. Leaf numbers refer to the age rank of leaves within the canopy. Leaf 0 is the spear leaf, leafl the next oldest leaf, etc. As new leaves emerged, they were assigned numbers of $-1,-2$, etc., according to the order of their emergence. Differences between means within a sampling time (month), as determined by analysis of variance, are indicated above the $+\mathrm{B}$ bar (Ns, * ${ }^{* *}$, and *** indicate non-significance or significance at $P=0.05,0.01$, and 0.001 , respectively). Vertical lines on bars represent SES. $\mathrm{n}=6$ replicate samples per treatment.
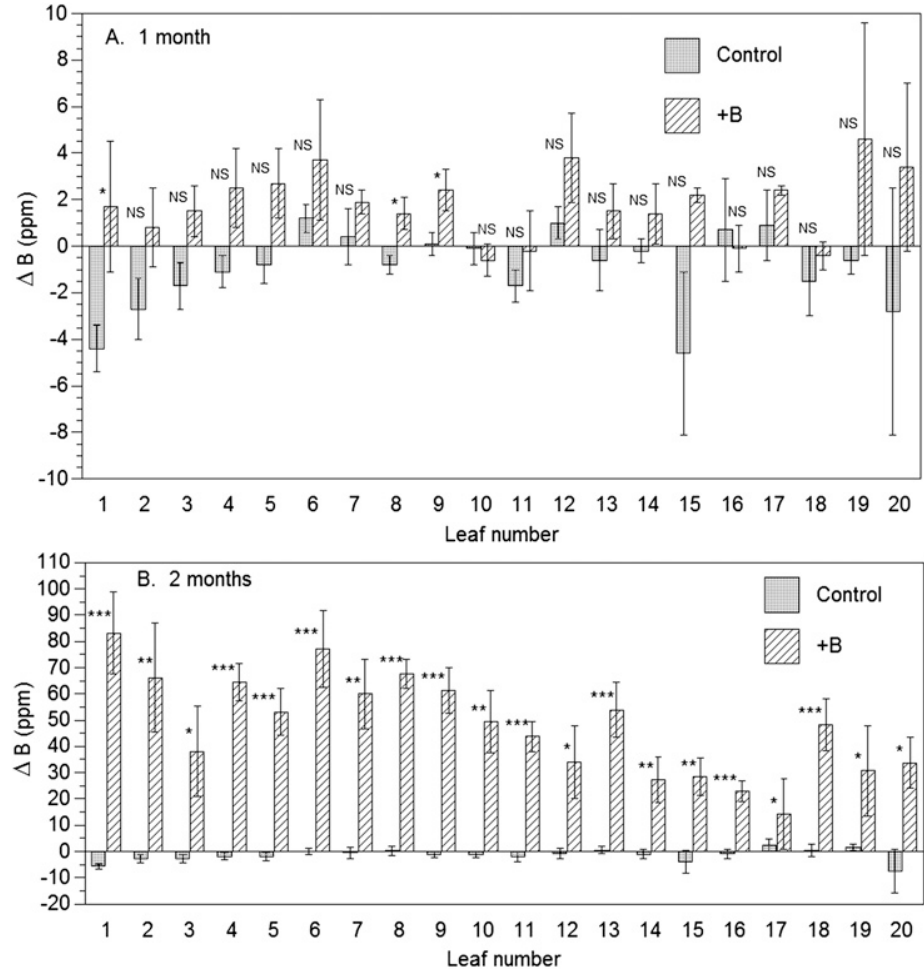

Fig. 3. Effects of soil-applied boron (B) on change in foliar B concentrations $(\Delta \mathrm{B})$ of leaves 1 through 20 of coconut palm at 1 (A) or 2 (B) months after application. An asterisk over the second bar in a pair indicates significance of analysis of variance (NS, *,**, and *** indicate non-significant or significant at $P=0.05,0.01$, and 0.001 levels, respectively). Vertical lines on bars represent SES. $\mathrm{n}=6$ replicate samples per treatment.

When Solubor was applied to the leaf axils, there were no significant increases in leaf 2 B concentrations until 3 months after application (data not shown) and increases were small $(\approx 5 \mathrm{ppm})$ compared with soiltreated plants. Small but usually significant increases in leaf $\mathrm{B}$ concentrations were also found in new leaves produced 2 to 6 months after treatment. Changes in B concentrations for older leaves at 2 months after application were also much smaller than for soil-treated palms and were significant for only approximately half of the leaves (data not shown). The reduced effectiveness of axil-applied $\mathrm{B}$ may have multiple causes. First, the total amount of B applied per tree through leaf axils $(225 \mathrm{mg})$ was much less than that applied to the soil $(35 \mathrm{~g})$. Second, the hard waxy surface of the petiole and leaf bases of coconut palm is not likely to be very permeable to water-soluble nutrients. Rajaratnam (1972b) also found minimal uptake of B from axillary application in African oil palm and experimentally demonstrated that axillaryapplied B was taken up by the palms only after being washed into the soil by rainfall, where it was subsequently taken up by the roots.

In conclusion, B appears to be rather uniformly distributed among leaves within the canopies of coconut palms and among leaflets within a leaf, but within individual leaflets, B tends to accumulate toward the tips of leaflets. In palmate-leaved species such as paurotis palm, basal leaflets had higher concentrations of B than central leaflets, but like coconut leaflets, the terminal portions of each leaflet contain more $\mathrm{B}$ than basal or central portions.

When applied to the soil, B did not significantly increase leaf $\mathrm{B}$ concentrations until 2 months after application when all leaves showed significant increases in leaf B. Older leaves, however, increased significantly less than younger leaves at that time. Leaves produced 2 to 6 months after treatment also had significantly higher $\mathrm{B}$ concentrations than similar-aged untreated palms. Although application of B solutions to the leaf axils significantly increased $\mathrm{B}$ concentrations in most leaves after 2 months, the amount of the increase was much less than that obtained from soil applications. Thus, there appears to be no advantage to applying $B$ to the axils of palm leaves when soil application is both efficient and effective.

\section{Literature Cited}

Amalu, U.C.D.O.A. and U. Omoti. 1988. The distribution of nutrient elements in the leaves of Nigerian tall coconut. Nigerian J. Palms and Oil Seeds 9:2-15

Broschat, T.K. 1997. Nutrient distribution, dynamics, and sampling in coconut and Canary Island date palms. J. Amer. Soc. Hort. Sci. 122:884-890.

Broschat, T.K. 2007a. Boron deficiency symptoms in palms. Palms 51:115-126.

Broschat, T.K. 2007b. Boron deficiency, phenoxy herbicides, stem bending, and branching in palms-Is there a connection? Palms 51:161163.

Brown, P.H. and B.J. Shelp. 1997. Boron mobility in plants. Plant Soil 193:85-101.

Corrado, F., P. Quencez, and B. Talliez. 1992. Boron deficiency in oil palm: Symptoms and corrections. Oléagineux 47:719-725.

Dickey, R.D. 1977. Nutritional deficiencies of woody ornamental plants used in Florida landscapes. Univ. Fla. Agric. Expt. Sta. Bull. 791.

Elliott, M.L., T.K. Broschat, J.Y. Uchida, and G.W Simone. 2004. Compendium of ornamental 
palm diseases and disorders. Amer. Phytopath. Soc. Press, St. Paul, MN.

Huang, L., R.W. Bell, B. Dell, and J. Woodward. 2004. Rapid nitric acid digestion of plant material with an open-vessel microwave system. Commun. Soil Sci. Plant Anal. 35:427-440.

Kamalakshiamma, P.G. and M. Shanavas. 2002. Boron deficiency in coconut-Symptoms and corrections. Indian Coconut J. 32:1-5.

Keren, R. 1996. Boron, p. 603-626. In: Bartels, J.M. (ed.). Methods of soil analysis. Part 3. Chemical analysis. Soil Sci. Soc. Amer., Madison, WI.

Kohl, H.C., Jr. and J. Oertli. 1961. Distribution of boron in leaves. Plant Physiol. 36:420-424.
Mills, H.A. and J.B. Jones, Jr. 1996. Plant analysis handbook II. A practical sampling, preparation, analysis, and interpretation guide. MacroMicro Publishing, Athens, GA.

Oertli, J.J. 1994. Non-homogeneity of boron distribution in plants and consequences for foliar diagnosis. Commun. Soil Sci. Plant Anal. 25:1133-1147.

Rajaratnam, J.A. 1972a. The distribution and mobility of boron within the oil palm, Elaeis guineensis L. I. Natural distribution. Ann. Bot. (Lond.) 36:289-297.

Rajaratnam, J.A. 1972b. The distribution and mobility of boron within the oil palm, Elaeis guineensis L. II. The fate of applied boron. Ann. Bot. (Lond.) 36:299-306.
Rajaratnam, J.A. 1973. Application, absorption, and translocation of boron in oil palm. III. Leaf analysis for diagnosing boron requirements. Exp. Agr. 9:257-262.

Reuter, D.J. and J.B. Robinson. 1986. Plant analysis an interpretive manual. Inkata Press, Melbourne, Australia.

Reuther, W. 1948. The mineral composition of date palm foliage. Proc. Amer. Soc. Hort. Sci. $5: 137-155$.

Tomlinson, P.B. 1990. The structural biology of palms. Clarendon Press, Oxford, UK.

von Uexkull, H.R. and T.H. Fairhurst. 1991. The oil palm: Fertilizing for high quality and yield. Intl. Potash Inst. Bull. No. 12. 